\title{
FAPESP: presente e futuro
}

\section{DEPOIMENTOS}

\begin{abstract}
A ÁREA De POlítica Científica e Tecnológica do Instituto de Estudos Avançados da USP, coordenada pelos professores Walter Colli e Alberto Carvalho da Silva, realizou uma reunião no IEA, em agosto deste ano, com o objetivo de ouvir opiniões a respeito das questões que estão colocadas para a Fundação de Amparo à Pesquisa do Estado de São Paulo (FAPESP) diante dos desafios atuais da realidade brasileira. Na abertura da sessão, o professor Alfredo Bosi, editor de ESTUDOS AVANÇADOS, ressaltou que o debate seria registrado na revista e teria como tema central Dilemas e alternativas da FAPESP. "O tema é complexo e por isso houve inicialmente um primeiro encontro, destinado a recolher opiniões e depoimentos com alguns dos fundadores da FAPESP. Mas como o nosso interesse maior está no exame dos problemas atuais - isto é, como a política científica e tecnológica deve se definir hoje - acertamos o debate que iniciaremos aqui. Parece-me claro que o centro da discussão reside nos dilemas e nas alternativas da FAPESP de hoje em diante", afirmou Bosi.
\end{abstract}

Leia, a seguir, o resumo da transcrição dos depoimentos que foram dados, oralmente ou por escrito, pelos participantes.

Walter Colli (diretor do Instituto de Química da USP e membro do Conselho Deliberativo do IEA-USP) - Há muito se discute a necessidade de maior interação entre o setor produtivo e as universidades, entre a ciência propriamente dita e a produção industrial, tendo em vista, principalmente, aumentar a produtividade do país em áreas de ponta. Participei de numerosas discussões mas sinto que ainda não há um entendimento sobre como devemos avançar. Espero que este grupo consiga diagnosticar bem o que ocorre no país e possa fazer sugestões de como proceder. Em minha opinião, essa interação é fundamental para que o Brasil possa dar um salto qualitativo na produção industrial.

Alberto Carvalho da Silva (professor honorário do IEA-USP) - O grupo aqui reunido foi formado com a idéia de se ter a participação de pessoas com experiência na investigação científica básica, outras com experiência em pesquisa e desenvolvimento ligadas a empresas e ainda outras com experiência na administração de agências que apóiam os desenvolvimentos científico e tecnológico. O objetivo deste debate é chegar a idéias gerais e, talvez, a sugestões de uma linha de atuação que poderíamos oferecer à FAPESP. Esta tem uma tradição muito grande de apoio à pesquisa básica, partindo do entendimento que a investigação científica é uma espécie de capacidade que a sociedade utiliza na medida de suas necessidades, utilizando as estruturas científicas montadas. Hoje em dia essa tese não é mais aceita, por agora se entender que o desenvolvimento econômico e o científico se interagem, um influindo sobre o outro. Infelizmente, apesar de 
convidados, por diversas razões aqui não se encontram Milton Campanário, do IPT nem Marisa Cordeiro, do Instituto de Botânica da USP.

Alberto de Castro (diretor do Instituto de Pesquisas Tecnológicas - IPT) A Lei Orgânica número 59.118, de 18 de outubro de 1960, que instituiu a FAPESP, estabeleceu em seu Artigo 20: "É finalidade da Fundação o amparo à pesquisa do Estado de São Paulo". Portanto, o critério de amparo a projetos é fundamentalmente o do avanço do conhecimento científico. Entretanto, os dois tópicos da lei mostram que os seus instituidores se preocupavam também com a aplicação dos conhecimentos científicos. O Artigo $5^{\circ}$, sobre os recursos da Fundação, diz: "As parcelas que lhe forem contratualmente atribuídas dos lucros decorrentes da exploração de direitos sobre patentes resultantes das pesquisas feitas com o seu auxílio"; e o Artigo 12, $\$ 1^{\circ}$, diz: "Na Assessoria Técnico-Científica deverão estar representados os diversos setores de pesquisas da ciência e da tecnologia".

Com exemplar atuação nesses seus mais de 30 anos, a FAPESP constituiu um paradigma para outras instituições, nacionais e estrangeiras. Amparando prioritariamente a pesquisa científica, soube, ao mesmo tempo, dar apoio a muitos e importantes projetos de natureza tecnológica.

Orienta-se no sentido de não separar, nem mesmo a ciência fundamental, dos demais componentes do complexo ciência e tecnologia. Esse enfoque foi exposto de maneira muito sugestiva por M.R.c. Greenwood, diretor-associado para Ciência, do Office of Science and Technology Policy, dos EUA, em um colóquio anual da A.A.A.S (C\&EN, 25 de abril de 1944, p. 35): "A ciência fundamental é componente do núcleo de uma rede (network) integrada, e não um segmento destacável de um modelo linear. Hoje o complexo ciência-tecnologia parece-se mais com um ecossistema do que com uma linha de montagem. Todas as partes do sistema acham-se interligadas de múltiplas maneiras, e mudanças em um dos seus componentes provoca efeitos através de todo o sistema". Na mesma reunião, P.A. Griffiths, presidente do Institute of Advanced Studies, de Princeton, ressaltava este enfoque e um outro lado do enfoque moderno - a crescente preocupação com os efeitos sociais das atividades de ciência e tecnologia: "Nós certamente estaremos mais perto de atender às necessidades essenciais da sociedade, aí incluída a competitividade da economia global, se ligarmos de maneira criativa as trajetórias duais da ciência básica e da inovação tecnológica".

O assunto exposto arrasta consigo tal número de outras importantes questões que o seu equacionamento requereria discussão em um ambiente mais amplo, no qual estivesse em análise todo o complexo ciência-tecnologia do Estado. Cabe ressaltar que o capítulo de Ciência e Tecnologia da Constituição Estadual, de 1989, inclui diretrizes válidas até hoje, na minha opinião, e que deveriam ser consideradas nesse contexto.

Pelo seu Artigo 268, $\$ 1$ 1 : “A pesquisa científica receberá tratamento prioritário do estado, diretamente ou por meio dos seus agentes financiadores de fomento, com o objetivo do bem público ao lado do objetivo de progresso da ciência". 
$\mathrm{O} \$ 1^{\circ}$ do Artigo 269 estabelece amplas diretrizes para a "política estadual científica e tecnológica... a ser definida pelo Conselho Estadual de Ciência e Tecnologia, cujas estrutura, organização, composição e competência serão definidas em lei", de acordo com o $\$ 2^{\circ}$ do mesmo Artigo.

O Artigo 270 prevê o apoio e o estímulo, a serem definidos em lei, a "instituições e empresas que invistam em pesquisa e criação de tecnologia".

Finalmente, o Artigo 271 determina que o estado destine à FAPESP "no mínimo um porcento de sua receita tributária... como renda de sua privativa administração para a aplicação em desenvolvimento científico e tecnológico". A finalidade, tal como estabelecida neste artigo da Constituição, pode ser interpretada como muito mais abrangente do que a prevista na lei de criação da FAPESP, o que sugere a sua revisão, incluindo diretrizes mais amplas. Isso, porém, dentro de um plano que retome todas as diretrizes da Constituição para Ciência e Tecnologia, à luz da experiência dos últimos anos, e estabeleça um conjunto de leis harmônicas estruturando o complexo ciência-tecnologia do estado como um verdadeiro sistema. Dentro desse sistema, a FAPESP poderia ser integrada a todos os circuitos de informação, inclusive com assento no conselho de cúpula do sistema; dessa maneira, usando a prerrogativa constitucional de "privativa administração", ela poderia dirigir as suas atividades em sintonia com o andamento geral do sistema.

\section{Vínculo da Ciência com a Tecnologia}

Eduardo Krieger (presidente da Academia Brasileira de Ciências e diretor da Unidade de Hipertensão-Instituto do Coração da Faculdade de Medicina da USP) - Hoje não se pode mais encarar a ciência desvinculada do sistema de tecnologia. Por isso, a FAPESP deve saber qual a sua inserção dentro desse sistema e o que ele representa para o sistema de ciência e tecnologia estadual. Para ilustrar o que a FAPESP deve enfrentar nesta nova fase, lembro que, quando comecei a minha carreira científica, há quase 40 anos, a situa-ção era muito tranquila. A FAPESP apoiava a ciência básica, apoiava a Universidade, todos nós trabalhando para aumentar a capacitação científica nacional. Isto era bom e deveria ser continuado. O problema é que, atualmente, esse procedimento deve ser entrosado com as necessidades imediatas porque a aplicação passou a suscitar na universidade, na Ciência, uma interação imediata, pronta, e não dá mais para considerá-las como sistemas distantes, uma esperando que a outra se desenvolva de forma autônoma.

Poder-se-ia perguntar em que a Ciência pode ser utilizada? Primeiramente, é na educação: na universidade, na graduação e na pós-graduação, mas também na educação básica. Acho, portanto, que a FAPESP vai ter de olhar carinhosamente se realmente está colaborando de maneira eficiente para formar os recursos humanos qualificados através da graduação na universidade e, também, na educação básica. Temos, realmente, indicadores das necessidades de recursos humanos qualificados? O setor produtivo tem de dar elementos porque não é a universidade sozinha, nem a ciência básica isoladamente que saberão sobre as necessidades globais. Apesar de saber quantos engenheiros, quantos médicos 
etc., precisamos, é em função do que se pretende fazer no setor tecnológico que novas modalidades, novos conhecimentos, novas preparações de recursos humanos qualificados são necessários. A FAPESP, conseqüentemente, tem que estar atenta para aspectos como a pesquisa que ela apóia, o uso da ciência como atividade educacional e se ela própria está cumprindo o seu papel na formação dos recursos humanos qualificados necessários para o desenvolvimento. A educação básica é um dos setores do qual a comunidade científica estava um pouco distante. No entanto, o avanço da Ciência é tão rápido que a comunidade científica deve se envolver na reciclagem do pessoal encarregado da educação básica em todos os níveis, incluindo a educação técnica.

O segundo ponto é o da transferência do conhecimento para o setor produtivo. Não vou me deter no aspecto de transferência para o setor industrial que depende de políticas industriais, incentivos fiscais etc. Uma das preocupações da comunidade porém e, seguramente, da FAPESP, é fazer a ligação universidade/ empresa, o mais rapidamente possível. Mas, há também uma transferência de conhecimento fundamental e que nós não estamos explorando adequadamente. Trata-se do setor público, na área federal os ministérios e na área estadual as diferentes secretarias. Temos realmente projetos para transferir conhecimentos para os setores de saúde, agricultura etc., por meio da interação da universidade com os institutos de pesquisa e tecnológicos do Estado? Mesmo dentro da própria universidade, eu destacaria, por exemplo, na área de saúde, o Hospital Universitário, local que precisa de ciência e tecnologia para melhor realizar a assistência médica. Temos de desenvolver projetos para que os nossos hospitais universitá-rios, pelo embasamento científico, tenham maior competência para solucionar problemas, utilizando os instrumentos de ciência e tecnologia. Despendemos enorme soma de recursos em importações de medicamentos e equipamentos; é preciso que alguém faça uma triagem crítica para saber o que nos interessa, o que não nos interessa, o que é mais adequado a nossa população.

Nessa nova fase, a FAPESP tem de reanalisar permanentemente, por meio do seu Conselho Superior, qual é o seu papel dentro do sistema de ciência e tecnologia do estado, interagindo com a Secretaria de Ciência e Tecnologia e o Conselho Estadual de Ciência e Tecnologia. Está muito bem aparelhada e tem enorme tradição em fazer as coisas bem feitas, mas basicamente no apoio à pesquisa básica, o que tem de ser mantido. Ela poderá absorver novas responsabilidades, contando com a dotação fixa de $1 \%$ da receita do estado? Ou vai colaborar, por seu know-how, com a Secretaria de C\&T, a quem compete procurar novas fontes de recursos? Lembro que isso está ocorrendo também na área federal com o CNPq e o Ministério de Ciência e Tecnologia, de criação mais recente. O CNPq tem o seu Conselho Deliberativo equivalente ao Conselho Superior da FAPESP, mas agora, no sistema de ciência e tecnologia federal, há o Conselho Nacional de Ciência e Tecnologia, recém-instituído, que procurará articular as políticas dos vários ministérios, incluindo-se naturalmente as ações do CNPq. Coisa semelhante deve ocorrer em nível do nosso estado, quando a FAPESP poderá articular suas políticas dentro de um quadro de C\&T mais amplo. 
A minha colaboração é mais no sentido de lembrar que estamos vivendo nova época, na qual a FAPESP deve ser considerada peça importante dentro de um sistema de ciência e tecnologia estadual. Ela existe há muito tempo e na sua participação no sistema ela não pode ser descaracterizada; ela precisa continuar fazendo aquilo que sabe fazer e é a única que faz: o apoio à pesquisa. O estado gasta cerca de $10 \%$ nas universidades e $1 \%$ na FAPESP, que mantém a pesquisa na universidade e assegura a formação de recursos humanos qualificados. O desenvolvimento tecnológico se faz através de profissionais treinados pela universidade e a sua qualidade depende da Ciência. Só isso já justificaria o papel da FAPESP no sistema C\&T. O desafio atual é preservar a sua função histórica e fazer com que ela participe de maneira mais ampla, com a sua reconhecida capacidade, no sistema de ciência e tecnologia do estado.

\section{Retorno dos investimentos}

Fernando Reinach (professor do Instituto de Química da USP) - A FAPESP atua hoje em pequena parte de um ciclo conhecido: inicialmente a geração do conhecimento básico; depois, pequena parte desse conhecimento básico transforma-se em alguma coisa aplicada; em seguida, uma pequena fração vira tecnologia e, dessa, uma parte vai gerar produtos. Por aí é que se justifica todo o investimento em ciência básica, que é a grande tradição da FAPESP. Se a sociedade não entender de alguma maneira que o resultado das pesquisas apoiadas pela FAPESP se transforma em alguma coisa útil para todos, a tendência será acabar com agências como a FAPESP. Ela gasta o dinheiro do contribuinte e tem o dever de a ele dar satisfações. O retorno social e/ou econômico de um investimento em pesquisa bem sucedido e suficientemente grande para compensar largamente o grande número de investimentos sem retorno, inerentes à ciência básica.

A FAPESP tem longa folha de serviços no apoio à ciência básica, mas, como já expliquei, existem diversas etapas entre a ciência básica e a produção. Seria um erro da parte da Fundação tentar financiar projetos já na etapa da produção. O PADCT falhou quando tentou identificar os grandes problemas da nação investindo de forma direcionada, fazendo promessas que nunca foram cumpridas.

Devemos esclarecer ao sistema empresarial que a infra-estrutura de ciência e tecnologia de São Paulo oferece oportunidades de cooperação para melhorar a competitividade do setor produtivo paulista. E que se os empresários não extraírem vantagens dessa oportunidade, ou demorarem muito em fazê-lo, correm sérios riscos. Apesar da integração com as metas da sociedade ser fundamental para a sobrevivência da universidade e da FAPESP, é necessário tomar cuidado na hora de expandir a Fundação na direção de financiar pesquisas voltadas para a área tecnológica. Primeiramente, deve-se identificar os critérios de excelência que devem ser utilizados na ciência aplicada, como critérios relacionados a custos e retorno de investimentos - pontos que raramente são considerados em projetos de pesquisa em ciência básica. Nesta área a FAPESP tem muito a aprender para não passar por incompentente. 
O principal risco quando agências, como a FAPESP, entram na área de apoio a pesquisa tecnológica é se converterem em agência de subsídios à indústria. Quando se pretende fazer a integração entre universidade e empresas correm riscos, tanto a universidade como as empresas. Destaco um ponto importante referente à falha na estratégia adotada pelo PADCT: lançar editais em áreas pré-determinadas para que os interessados apresentem projetos direcionados. Considero essa política errada. Penso que a FAPESP não deve identificar temas. A escolha dos temas de trabalho deve ser feita pelas empresas e membros da universidade nele envolvidos.

A FAPESP já está fazendo algumas experiências interessantes e que vão trazer algumas lições, mas, no lado empresarial, o número de interlocutores que compreendem a relação entre ciência, tecnologia e competitividade é pequeno. É preciso identificar empresários que tenham um perfil adequado, sejam capazes de se desligarem de seus interesses pessoais e possam colaborar com a FAPESP na avaliação dos projetos. A Fundação tem de agir com cuidado a fim de encontrar os partners que compreendem o processo em andamento no Brasil. Finalmente, penso que o estado precisa entender que as universidades e a FAPESP representam um patrimônio para o desenvolvimento de São Paulo. Espero que o governo e as empresas saibam recorrer adequadamente a esse patrimônio.

\section{Interação universidade/empresa}

Francisco Romeu Landi (diretor-presidente da FAPESP e ex-diretor da Escola Politécnica da USP) - É muito interessante para a FAPESP que haja uma discussão dessa natureza na comunidade científica. Com clareza de idéias, os novos programas obterão resultados imediatos. A FAPESP conseguiu ao longo dos seus 34 anos, tradição de eficiência e respeito da comunidade pela sua atuação. Um encontro desta natureza contribuirá para o seu aperfeiçoamento.

A interação universidade-empresa tem sido melhor utilizada pelas áreas profissionalizantes, em particular pela engenharia, que, se pode dizer, é o braço da universidade para ações desse tipo, mas que hoje já se estendeu à computação, farmácia, química, física, economia, administração etc.

Importante nessa relação é a harmonia natural dos conflitos que podem resultar das diferentes missões da universidade e da empresa. A universidade visa à formação de recursos humanos e à geração do conhecimento, que normalmente exigem prazos longos. A empresa participa da competição do mercado e necessita de prazos curtos. A pesquisa tem um custo natural. A empresa visa o lucro. Daí a importância de haver, num processo de parceria, a necessidade de respeito mútuo, ou seja, de uma respeitar a missão da outra.

Para a universidade, há um importante subproduto nesse aprendizado: é o domínio das técnicas de administração eficiente da pesquisa. A parceria ajuda a diminuir a carga ideológica de alguns acadêmicos e o imediatismo de alguns empresários. A experiência da FAPESP com os seus programas de parceria tem 
sido muito boa. Têm sido aprovados projetos de excelente qualidade que, desde já, apontam para um feliz sucesso. Ao lado de ser importante forma de geração de empregos, de desenvolvimento, de impostos, de organização social e administrativa, a empresa é também a base da inovação tecnológica, como resultado de competição.

O fortalecimento da empresas é importante para o desenvolvimento de uma nação, e faz parte de uma estratégia governamental. Gradativamente devemos mudar o nosso enfoque da empresa. Há necessidade de entendê-la como convergência de interesses e não como ponto de encontro de conflitos sociais.

É ela importante interface também entre o sistema C\&T e a sociedade. Também, em geral, é a primeira a sentir as necessidades da sociedade e de lhe oferecer o produto ou serviço demandado. É estratégico entender a interface como parceria da inovação e da realimentação do próprio sistema.

É de se notar, por outro lado, que a inovação tecnológica ocorre principalmente na pequena e média empresa. Provavelmente porque a flexibilidade seja condição básica para a inovação. É fato, nos Estados Unidos, que 80\% das inovações são feitas por pequenas e médias empresas e só depois adquirida pela grande.

A inovação tecnológica constitui uma estratégia para as empresas. Já existem diversas empresas em áreas de ponta, nas quais mais de $50 \%$ do faturamento referem-se a produtos com apenas três ou quatro anos de existência. Em certas áreas, nem mesmo patentes ou direitos autorais são garantias. O que conta é estar na frente, inovando sempre.

A experiência tem mostrado também que nos países mais desenvolvidos, e onde há maior competitividade, a empresa é a grande investidora em tecnologia. Nos países de menor competitividade, o estímulo precisa ser criado. É de se observar, contudo, que mesmo naqueles países mais desenvolvidos, os órgãos públicos dispõem de programas de apoio à pequena empresa.

A união dos recursos humanos e laboratoriais da universidade com a eficiência e agilidade da empresa constituem as bases para a aplicação dos investimentos financeiros, trazem para a universidade a real dimensão das necessidades da sociedade e, para a empresa, os recursos humanos e laboratoriais que dificilmente obteria de outra forma. Ao lado do programa de parceria universidade-empresa, já em andamento na FAPESP, outros precisam ser criados, capazes de estimular a inovação tecnológica e o desenvolvimento da Ciência. Precisam ser criadas, também, formas que permitam aos grupos de pesquisa participar financeiramente da inovação, não sob o aspecto de vantagens pessoais, mas como fortalecimento institucional.

Não é justo que uma empresa aufira sozinha as vantagens resultantes da pesquisa; é necessário também que se criem condições de continuidade para o grupo de pesquisa continuar seu trabalho. 


\section{Inovação é um processo cultural}

Guilherme Ary Plonski (Núcleo de Política e Gestão Tecnológica da USP) Quero registrar, primeiro, que é um privilégio participar de uma reunião na qual pensamos oferecer recomendações para aprimorar uma instituição que vai indo muito bem, e não, como freqüentemente acontece, debatendo sobre como tirála do fundo do poço. É também uma situação excepcional discutir a colaboração entre o setor científico-tecnológico e o setor empresarial com a participação de representantes qualificados de ambos os setores e das agências. Com relação à experiência internacional, o que se verifica é a inovação, longe de ser um processo linear, ser um processo complexo. Ela pode surgir de muitas fontes, sendo a universidade, através da pesquisa original, apenas uma delas.

A inovação é um processo cultural, que envolve aprendizagem e novos valores. Os resultados da inovação dependem de três fatores: existência de uma estratégia, competência na gestão de recursos e articulação interinstitucional. É neste sentido que se fala hoje não mais em sistema nacional de ciência e tecnologia, mas em sistema nacional de inovação.

Como destacou o professor Alberto de Casto, inovação é mais do que C\&T. A comparação entre Estados Unidos e Japão mostra bem a importância da adoção de uma estratégia e do uso dos recursos a ela ajustados. Os Estados Unidos investem muito mais do que o Japão em C\&T, e sua produção acadêmica é muito maior. Todavia, do ponto de vista da inovação, o Japão teve um desempenho muito melhor que os EUA nas últimas décadas. Os resultados da cooperação universidade/empresa dependem mais da competência na gestão da interface e dos projetos, ou programas de cooperação, do que da existência de recursos ou de eventuais dificuldades científicas.

Quero fazer algumas recomendações. A primeira é que a FAPESP abra uma linha de apoio à gestão da tecnologia, como contribuição explícita para que seus recursos sejam usados da maneira mais eficiente possível.

A segunda é que ela contribua, de alguma forma, para a maior disponibilidade de informações tecnológica e gerencial, com prioridade para micro e pequena empresas visando a formas modernas de comunicação.

A terceira recomendação é procurar restabelecer na opinião pública o conceito de que o desenvolvimento tecnológico é altamente benéfico, desfazendo a tendência crescente de responsabilizá-lo pelo desemprego, pela poluição e por outros males. Essa percepção da importância da tecnologia e da inovação deve permear as negociações para o estabelecimento de empresas estrangeiras no país, com a condição de que desenvolvam aqui tecnologia. Trata-se, em última análise, de valorizar o conhecimento científico e tecnológico como condição para o progresso e a solução de problemas reais. Outra recomendação é que a FAPESP apoie a pesquisa pré-competitiva, na qual participem várias empresas e instituições de pesquisa. Trata-se de estratégia que deu bons resultados em outros países. 
A última recomendação é a de contribuir para a criação de um sistema paulista de inovação, em que se procure a integração das instituições e a identificação dos gargalos existentes: sem gerar projetos dispendiosos que rapidamente se defasam, mas criando um sistema de indicadores que permitam acompanhar a evolução dos problemas e servir de orientação para a formulação de políticas, e de como os diversos atores envolvidos devem atuar para encaminhar soluções.

Finalmente, penso que a FAPESP deveria procurar articular-se com outras entidades de fomento, de modo que umas supram as limitações de outras, com as vantagens de cada uma delas. Através dessas parcerias a Fundação poderia aumentar ainda mais os serviços que vem prestando.

\section{Novos programas da Fundação}

José Fernando Perez (diretor científico da FAPESP e professor do Instituto de Física da USP) - A contribuição que eu sugeriria ficou superada pela dinâmica da reunião. Muito do que pretendia dizer, de uma forma ou de outra, já foi dito. Por outro lado, o que já foi dito aqui mostra uma consciência muito clara das necessidades existentes e reforça nossa percepção quanto aos caminhos que a FAPESP vem trilhando apontarem na direção correta.

Inicialmente devemos enfatizar que a palavra pesquisa é essencial e nunca deve ser omitida quando o contexto é a FAPESP, pois ela é o grande demarcador das fronteiras de atuação da instituição. Embora seja vital encontrar os mecanismos de transferência de conhecimento para o governo e para a indústria, a ação da FAPESP deve se circunscrever ao apoio à pesquisa, não devendo tentar substituir a ação do governo e das empresas.

Os novos programas criados pela FAPESP nos últimos anos nascem de um diagnóstico da situação atual do desenvolvimento da pesquisa científica e tecnológica no país. A esse propósito recomendo a leitura do texto A Ciência no Brasil, de J. Leta e Leopoldo de Meis, no qual é feita uma profunda reflexão sobre o panorama da ciência brasileira. Usando a mesma base de dados do ISI, utilizada pela Folha de S. Paulo na polêmica publicação sobre os melhores pesquisadores brasileiros, esse estudo mostra que a ciência brasileira teve expressivo crescimento nos últimos 13 anos. Mostra também que a qualidade da nossa ciência, registrada nessa base de dados quando avaliada pelo seu impacto, bem como a sua dispersão entre as diferentes áreas, reproduz o padrão médio internacional. A nossa ciência é isomorfa à ciencia dos países desenvolvidos, a grande diferença reside na escala do nosso sistema de pesquisa, mais especificamente no pequeno número de pesquisadores no Brasil. Somos poucos pesquisadores. Ainda recentemente, no encontro de bioquímicos em Caxambu, ouvi depoimentos unânimes de que falta gente para ocupar todos os estágios que levam da pesquisa básica ao desenvolvimento tecnológico. E nessa área, Bioquímica, a distância conceitual e temporal entre a pesquisa básica e sua transformação em tecnologia é cada vez menor: precisamos de boa ciência básica, para fazermos boa ciência aplicada e boa biotecnologia. 
Outro elemento óbvio de diagnóstico, que já foi mencionado várias vezes nesta reunião, é o próprio motivo de sua realização: o sistema de pesquisa está fracamente acoplado ao sistema de tecnologia e temos influenciado pouco as políticas públicas. Além disso, existem preconceitos de natureza ideológica dentro do ambiente acadêmico quanto ao fortalecimento dessas interfaces. Do ponto de vista do governo e das empresas há grande ceticismo e desconhecimento ainda maior quanto ao potencial de eficiente contribuição do sistema acadêmico. Por outro lado, não há tampouco no país uma cultura de pesquisa em ambiente empresarial.

A FAPESP tem de enfrentar esses desafios de forma ativa. Há necessidade de o sistema de pesquisa crescer em todos os ambientes, dentro das instituições de pesquisa, no ambiente empresarial e na interface entre os dois sistemas.

Os novos programas da FAPESP, criados nos últimos anos, considerados individualmente ou em seu conjunto, constituem a resposta institucional a esses desafios.

\section{Programa de Inovação Tecnológica}

O Programa de Inovação Tecnológica propõe-se, em sua versão inicial, a apoiar projetos de pesquisa voltados para a inovação tecnológica e desenvolvidos em parceria entre instituições de pesquisa e empresas. O programa de parceria não tem como objetivo subsidiar empresas e, por essa razão, pressupõe contrapartida real da empresa parceira.

Cada projeto é julgado do ponto de vista da inovação proposta. O programa não é para ser usado apenas para atividades de consultoria. Temos sido rigorosos nesta fase de implantação do programa, de forma a não propiciar a percepção errada a respeito de sua natureza e de seus objetivos. O programa vem crescendo lentamente, mas de forma controlada e nítida. O gerenciamento desse programa representa um aprendizado para a própria FAPESP.

Há estudos em curso sobre uma nova variante do programa de inovação tecnológica que se destinaria a apoiar projetos de pesquisa dentro de pequenas empresas.

\section{Programa FAPESP-Ensino Público}

Outro programa interessante é o da parceria Universidade-Escola Pública. $\mathrm{Na}$ primeira rodada foram contemplados 20 projetos num montante de R\$ 5 milhões para quatro anos. Apresentaram-se 150 solicitações. Na segunda roda$\mathrm{da}$, esperamos repetir o investimento. O programa pretende contribuir para a criação de uma cultura na qual os pesquisadores das diversas áreas do conhecimento se sintam co-responsáveis pelo Ensino Público em todos os níveis. São apoiados projetos de pesquisa desenvolvidos dentro do ambiente da escola parceira, a qual deve também contribuir para a melhoria da qualidade do ensino. 


\section{Programa FAPESP-Jovens Pesquisadores}

Outra iniciativa importante foi o programa de jovens pesquisadores em centros emergentes. Com ele se pretende oferecer uma perspectiva de trabalho aos pesquisadores que concluem sua pós-graduação, no país ou no exterior, e já documentam excelente potencial para coordenar projetos de pesquisa. São priorizadas solicitações que contribuam para a nucleação de novos centros de pesquisa.

\section{Centros de Ciência e Tecnologia}

Dentro da filosofia de conjugar atividades multidisciplinares de pesquisa científica ou tecnológica, atividades de transferência de conhecimento para o governo ou indústria e atividades de difusão científica e tecnológica em todos os níveis, um novo programa está sendo estudado para a criação de centros de ciência e tecnologia. O paradigma para esse programa são os centros de ciência e tecnologia criados pela National Science Foudation.

Há alguns exemplos de projetos de pesquisa financiados pela FAPESP que influenciaram significativamente políticas públicas. Um deles, emblemático, propôs estratégias alternativas para programa de vacinação destinado a erradicar a rubéola. A proposta foi adotada pela Secretaria da Saúde com sucesso e grande economia de recursos. Temos de ensinar o poder público a perceber o grande potencial de apoio a ser obtido no ambiente acadêmico que pode ser viabilizado pela FAPESP.

\section{Articulação do Sistema Nacional de Fomento}

Outro tópico que considero relevante ao se estudar a ação da FAPESP diz respeito à articulação do sistema nacional de fomento à pesquisa científica e tecnológica. Até recentemente as agências operavam de forma essencialmente independente. Estamos procurando tornar nossa ação complementar à das agências federais.

Mais do que isso, temos buscado ativamente uma cooperação. A FAPESP levou proposta de estadualização de uma fração dos recursos a serem aplicados no PADCT-III. Esses recursos seriam gerenciados pelas respectivas FAPs (Fundações de Amparo à Pesquisa Estaduais), que fariam a seleção das propostas a serem apoiadas, proveriam contrapartida adicional à federal e acompanhariam o desenvolvimento dos projetos. Com isso o sistema tornar-se-ia mais eficiente e as FAPs sairiam fortalecidas.

Para concluir esta breve apresentação, eu diria que a implementação dos novos programas da FAPESP tem constituído uma aprendizagem para a instituição. Talvez o grande desafio de curto prazo seja dotar esses programas do mesmo padrão de qualidade que se tornou marca registrada da fundação internacionalmente reconhecida. 


\section{Como apoiar as empresas}

Roberto Silva Waack (diretor da Associação Nacional de Pesquisa e Desenvolvimento das Empresas Industriais) - A FAPESP não deveria deixar de concentrar sua atuação no apoio à pesquisa com base no mérito avaliado pelos pares. É um dos poucos exemplos de competência nesse tipo de atividade no Brasil. Aproveito uma frase de Michael Hammer, publicada recentemente em revista nacional de negócios: "O segredo do sucesso não é prever o futuro, mas criar uma organização que prosperará em um futuro que não pode ser previsto". A missão histórica da FAPESP na formação de uma estrutura científica para dar apoio à sociedade em suas múltiplas demandas, vem ao encontro com a necessidade do setor empresarial em contar com uma base ampla e diversificada de conhecimentos.

Ainda, a FAPESP não deveria abandonar o Programa de Apoio à Capacitação Tecnológica das Universidades, Instituições de Pesquisa e Desenvolvimento e Empresas: Projeto de Inovação Tecnológica em Parceria, nos moldes em que vem sendo realizado.

Para este programa, sugiro a incorporação dos seguintes pontos:

- Implementar sistemática de seleção de setores com maiores chances de competitividade, fomentando-os. O objetivo é focalizar para aumentar a eficácia do programa. Como subproduto, o programa poderia fornecer subsídios para orientação estratégica empresarial, freqüentemente pouco preparada para conhecer o ambiente competitivo em que se insere. A sistemática deveria ser flexível e dinâmica, permitindo que os setores selecionados sejam eventualmente alterados em função de mudanças nas conjunturas nacional e internacional.

- Incluir, na sistemática de seleção de empresas e projetos, avaliação da capacitação empresarial em gestão tecnológica. No meu entender, esse é um dos maiores pontos fracos das corporações nacionais (incluindo aquelas que realizam algum esforço em P\&D). A consideração da matéria no processo seletivo estimularia direta e indiretamente as empresas a se sensibilizarem para incorporação de ferramentas de planejamento e administração tecnológica.

Finalmente, a FAPESP poderia atuar como mobilizadora e catalisadora de capital de risco privado para investimentos em projetos tecnológicos. Embora seja voz corrente que não há disponibilidade de capital de risco privado em nosso país, acredito que a situação deva mudar em curto prazo. O conhecimento e competência da FAPESP na avaliação de projetos de pesquisa (e agora tecnologia, em função do Projeto de Inovação Tecnológica em Parceria), é de fundamental importância para a avaliação do risco de empreendimentos que, de alguma forma, contem com a integração empresa-universidade/institutos de pesquisa. $\mathrm{O}$ setor bancário, atuante nas cada vez mais freqüentes operações de fusões e aquisições, poderia interagir com a FAPESP na avaliação do valor de negócios com 
forte base tecnológica. Em contrapartida, a FAPESP poderia atuar como disseminadora e mobilizadora de empreendimentos com boas chances de se tornarem atraentes para capital de risco. Evidentemente, o modus operandi de tal operação deverá ser definido detalhadamente.

Em síntese, acredito que a FAPESP deva se manter forte e concentrada nas atividades que historicamente vem realizando com grande competência. No que tange ao apoio ao setor produtivo de base tecnológica, deve manter o Projeto de Inovação Tecnológica em Parceria nos moldes em que se encontra hoje, acrescentando algumas modificações (foco dinâmico e gestão tecnológica). Por fim poderá, sem prejudicar sua atividade core, adentrar no mundo do capital de risco privado, ao qual certamente tem grande contribuição a dar.

\section{A universidade e o ensino básico}

José Mindlin (empresário) - Depois do que foi falado, parece evidente já existir um consenso de que o Brasil precisa de desenvolvimento científico e tecnológico. $\mathrm{O}$ fato de a FAPESP inicialmente ter concentrado sua atividade no campo da ciência básica é perfeitamente compreensível, porque foi numa época em que o Brasil vivia o período de substituição de importações e a tecnologia, de modo geral, vinha de fora, através de contratos de assistência técnica. Mas o Brasil de hoje é bem diferente. Penso que a FAPESP é uma das melhores instituições existentes no país. É um modelo, conseguiu resistir a numerosos governos e manter-se fora de influências políticas. Tive a oportunidade de participar de seus Conselhos Superior e, depois, quando secretário de Cultura, de Ciência e Tecnologia, dei-lhe todo apoio, sem nunca ter interferido em sua atuação. Não há dúvida que o apoio à tecnologia, que agora vem sendo dado, não só segue uma direção correta, como deveria ser intensificado. Acho, no entanto, que se deve pensar mais em inovação e em formação tecnológica, do que em apoiar a pesquisa no dia-a-dia da produção da empresa.

Na realidade, ainda não está superado, embora a situação tenha melhorado, o preconceito, de há muito existente, entre a empresa e a comunidade científica. Esta vê no empresário um ganhador de dinheiro, sem preocupação com os problemas sociais. O empresário, por sua vez, vê o cientista como vivendo no mundo da lua, como um poeta, desligado das realidades do dia-a-dia da empresa e da população. Fui um dos fundadores da UNIEMP, que está promovendo uma aproximação entre a universidade e a empresa, e seu esforço, acredito, já trazendo resultados.

Vejo na empresa não uma finalidade em si mesma, mas um instrumento de desenvolvimento social, com responsabilidades que vão muito além de seus objetivos diretos, entre as quais incluo o apoio à cultura e ao desenvolvimento científico e tecnológico do país. É claro que a empresa tem de ser rentável, para poder cumprir adequadamente suas responsabilidades sociais.

A questão da competitividade é fundamental, especialmente agora, com a globalização da economia e a abertura do país para a competição externa. Sempre 
procurei defender a idéia de que se deveria tentar conseguir que a empresa estrangeira fizesse pesquisa no Brasil, com pesquisadores brasileiros tendo acesso ao que por ela fosse feito aqui e no seu país de origem. Mas, como não tínhamos qualquer proteção à propriedade intelectual, era meio irrealista esperar que a empresa estrangeira aqui fizesse pesquisa. Hoje essa situação mudou. A proteção já existe, e pode-se pleitear à empresa estrangeira que faça pesquisa em nosso país. Isso não deveria, creio eu, ser imposto, mas induzido por exemplo, por certas vantagens, como preferência, em igualdade de condições, nas concorrências oficiais, para as empresas que estiverem fazendo pesquisa no Brasil.

Concordo que a FAPESP não deva financiar a produção, mas discordo quando se diz que $n \tilde{a} o$ é necessário trabalhar com a grande empresa, pois ela tem condições de fazer pesquisa que traga resultados a mais curto prazo.

Quanto à pequena e média empresa, salvo as formadas por cérebros, como, por exemplo, a Xerox ou a Polaroid, que começaram pequenas, e em parte, as de informática, que têm grande potencial de crescimento, mas, normalmente, sem condições financeiras de fazer pesquisa, o ideal seria as pequenas e médias empresas formarem um pool em cada setor industrial para realizar um esforço conjunto de pesquisa e desenvolvimento.

O papel da universidade na formação ou no aperfeiçoamento e reciclagem dos professores de ensino básico é, a meu ver, fundamental. É preciso valorizar a profissão do professor. Ele deve ser remunerado mais condignamente e tem que estar preparado.

No Brasil vivemos uma pirâmide invertida. Temos qualidade no alto, mas ela falta no ensino público básico. O que a FAPESP poderia, e aliás creio que deveria fazer nesse campo, em parceria com o empresariado, seria dar maior apoio ao ensino básico.

A questão de a universidade ser gratuita ou paga é polêmica. Sou favorável ao ensino gratuito, porém, é fundamental melhorar o ensino básico, para o aluno que freqüentou a escola pública poder enfrentar os alunos de cursos particulares, e com isso ter acesso à universidade. O ensino é uma obrigação fundamental do Estado, embora não seja exclusivo do estado.

Acho que está fora de questão reduzir o apoio da FAPESP à pesquisa básica. O Brasil não seria o que é hoje, se a FAPESP não tivesse existido. Formamos uma massa crítica, que pode ser ainda pequena e insuficiente, mas já é apreciável. Quando falo em apoio ao ensino básico, não estou propondo reduzir o que se dá às universidades, mas aumentar o que se destina àquele nível de ensino.

Quanto à relação entre pesquisa básica e pesquisa aplicada ao desenvolvimento, é óbvio que precisamos das duas. O problema é exclusivamente de dosagem. A alocação de recursos entre ambas não deve levar a que uma impeça o desenvolvimento da outra. Mesmo com todos esses problemas, vejo a FAPESP, e seu crescimento, com muito otimismo. 


\section{Preferência a tecnologias sociais}

Renato Papaleo (diretor-executivo da Associação Nacional da Pesquisa e Desenvolvimento das Empresas Industriais) - Devemos direcionar o apoio para os setores industriais nos quais o país tenha vantagens competitivas, além de apoiar projetos nas áreas não-competitivas nas quais o país não desenvolverá processo ou produto, mas precisará ter um grupo de excelência capaz de sustentar diálogos com experts internacionais, tanto técnica quanto comercialmente.

Ao se preparar um projeto, deve-se exigir que se tenha procedido a um varrimento exaustivo não só da literatura publicada em revistas técnico-científicas, mas principalmente em bancos de patentes. Ao mesmo tempo, é necessário criar na FAPESP linha direta com as empresas para que consultem, via Internet, bancos de patentes, promovendo a educação para o uso através de palestras e aulas práticas. Igualmente deve-se estabelecer acordo com INPI.

Deve haver um tratamento preferencial para as empresas que fazem uso das leis de incentivos fiscais. Um fundo de reembolso para os projetos de cunho tecnológico que deram certo precisa ser criado. O recurso só será a fundo perdido se o trabalho apoiado pela FAPESP não resultar em inovação de processo ou de produto. Outra coisa, devemos apoiar projetos que visem o desenvolvimento de tecnologias voltadas para o mercado interno, principalmente as tecnologias sociais (habitação, transportes, saúde, educação, alimentos). Não podemos perder o referencial de que $95 \%$ dos projetos apresentam inovações incrementais. Isto tem implicações sobre o montante de recursos que devem ser alocados nas universidades (fundo perdido) e quanto deve ser da responsabilidade da empresa.

Faço ainda mais quatro sugestões:

- Criar uma assessoria tecnológica com elementos do setor produtivo, que avaliarão os projetos e farão o seu acompanhamento durante o desenvolvimento.

- Procurar apoio de entidades não-governamentais, dedicadas à promoção do desenvolvimento tecnológico, na divulgação da FAPESP-TEC.

- Projetos envolvendo pequenas e médias empresas devem ser desenvolvidos por institutos de tecnologia e, grandes empresas, pela academia universitária, supondo que as PMEs enfrentam problemas técnicos menos complexos, às vezes, de simples trouble-shooting.

- Apoiar programas de desenvolvimento tecnológico de fornecedores, desde que estes programas sejam igualmente apoiados pela grande empresa.

\section{Alternativas da FAPESP}

Renato Rocha Vieira (professor da Escola Politécnica da USP) - As atividades da FAPESP representam significativa contribuição para a modernização das atividades industrial e agrícola do estado e do país. Essa contribuição torna-se 
cada vez mais importante porque não é possível, atualmente, manter os ritmos de aumento de produtividade, desempenho e qualidade em setor produtivo algum das sociedades civilizadas sem o apoio da dinâmica de inovação associada ao contínuo esforço na atividade de pesquisa, compatível com as dimensões e diversidade do setor produtivo.

Por outro lado, grande parte da eficiência da FAPESP deve-se à austeridade com que são geridos seus recursos e ao grande efeito catalisador e multiplicador de seus projetos. A ampliação do esforço da FAPESP nas áreas relacionadas ao setor produtivo apresenta a limitação de seus recursos serem relativamente pequenos face às necessidades.

Pode-se, todavia, sugerir novos mecanismos de maneira a ampliar as conseqüências do esforço de pesquisa no processo produtivo e nas áreas de ciência aplicada em geral.

Uma das formas para tanto é concentrar esforços naqueles mecanismos que significam ativar a interação universidade/instituto de pesquisa-empresa. Aspecto importante refere-se à identificação de temas de pesquisa mais relevantes como inovação tecnológica, ou solução de problemas que afetam a produtividade, ou desempenho e qualidade dos produtos em geral. A identificação desses temas depende de maior integração homem de produção/pesquisador.

Outro aspecto diz respeito à transferência dos resultados e informações do laboratório para a escala semi-industrial e industrial. A maneira mais efetiva é a transferência do pesquisador que, entretanto, não deve ser irreversível.

É possível, portanto, com os mesmos mecanismos nos quais a FAPESP tem experiência, ampliar as repercussões sobre o setor produtivo sem investimentos muito mais pesados que os atuais. Algumas inovações podem, entretanto, ser interessantes para aumentar as oportunidades e ativar as relações universidade/ instituto de pesquisa-empresa.

Além de projetos cooperativos de maior porte que devem ser estudados e detalhados caso a caso, podem ser estabelecidos alguns esquemas básicos relacionados à concessão de bolsas para pesquisadores desenvolvendo projetos cooperativos.

Mesmo sem maior conhecimento sobre a experiência da FAPESP em projetos interativos, relacionamos abaixo algumas alternativas:

- FAPESP: financia bolsas de pesquisa associadas ou não a mestrado, doutorado ou iniciação científica. Empresa: financia o custo operacional do projeto, incluindo a utilização de suas facilidades em laboratórios, oficinas e equipamentos industriais.

- FAPESP: financia bolsas ou pro-labore para professores ou pesquisadores dos institutos oficiais, para desenvolver projetos de pesquisa e cursos nas empresas na qualidade de professores ou pesquisadores visitantes. Em- 
presa: fornece facilidades laboratoriais, enre outras, e informações sobre os assuntos relacionados ao projeto.

- FAPESP: financia pro-labore a pesquisador da indústria desenvolvendo projeto de pesquisa e cursos específicos na universidade ou institutos de pesquisa. Empresa: libera o pesquisador para desenvolver o projeto conjunto e libera dados e informações relevantes, permitindo também o uso de suas instalações, importantes para o projeto, e cobre os custos de ensaios e experimentos.

- Instituto de pesquisa/universidade: responsável pelo projeto através de seus departamentos, pesquisadores ou professores orientadores; seus equipamentos são disponíveis dentro das regras correntes.

Tratando-se de envolvimento tripartite e mesmo quadripartite incluíndose o candidato à bolsa, será interessante que os projetos possam ser submetidos à aprovação parcial, à semelhança da carta de intenções, em algumas entidades financiadoras. Nessa situação poderão faltar candidatos a bolsas, cujos currículos serão submetidos posteriormente, ou até mesmo a empresa interessada, para um projeto já definido e com quadro completo de pesquisadores. 